\title{
Laryngocele masquerading as a soft tissue neck mass
}

\section{Dhungel K ${ }^{1}$, Gupta MK ${ }^{1}$, Ahmad K ${ }^{1}$, Sah PL ${ }^{1}$, Rauniyar RK ${ }^{2}$}

${ }^{1}$ Assistant Professor, ${ }^{2}$ Professor, Department of Radiodiagnosis and Imaging, B.P Koirala institute of Health Sciences, Dharan, Nepal

\begin{abstract}
Laryngocele is a rare entity which can clinically present as a neck mass and requires Computed Tomography (CT) and laryngoscopy for diagnosis. We present an interesting case of bilateral laryngocele in a 45 -year-old male presented clinically as hoarseness and left sided neck mass without any history of predisposing factors. Ultrasonography (USG) and $\mathrm{CT}$ features of laryngocele is also presented here.
\end{abstract}

Key words: Laryngocele; Cervical mass; Ultrasonography; Computed Tomography

L aryngoceles are abnormal dilations or herniations of the laryngeal saccules ${ }^{1}$. They communicate with the laryngeal lumen and are generally filled with air. They become clinically apparent when they are distended after air is forced into them or when they are filled with fluid.

Laryngoceles are fairly unusual diseases representing over $20 \%$ of the true submucosal lesions of the laryn $x^{2}$. Larry, a surgeon in Napoleon army, first described laryngocele in 1829; it was in Egypt that he first observed this type of swelling ${ }^{3}$.

The usual classification divides laryngoceles into internal, external and mixed types. Internal laryngoceles are those located medially to the thyrohyoid membrane and usually compress the false vocal cords causing hoarseness or airway obstructive symptoms. External laryngoceles extend through the thyrohyoid membrane, presenting as cervical masses. And Mixed (most commonest) laryngoceles present with both the internal and external components with their respective symptoms. An external does not occur without an internal component $t^{4}$.

Diagnosis is usually defined by computed tomography and /or laryngoscopy.

\section{Case report}

A 45 -year-old male patient salesman by occupation clinically presented with hoarseness, difficulty in swallowing and painless swelling on the left side of the neck for 15 days which was insidious in onset and gradually progressive with no history suggesting airway obstruction or increased intralaryngeal pressure.
On physical examination, a single soft, non tender, swelling of about $7 \times 6 \mathrm{~cm}$ was present in front of left sternocliedomastoid below angle of the mandible. Another small similar swelling was also noted on the right side of the neck.

As fine needle aspiration from the mass yielded only air, patient was brought to the radiology department for USG as well as USG guided Fine Needle Aspiration Cytology (FNAC).

USG of neck demonstrated a subcutaneous swelling just inferior to submandibular gland and medial to the carotid bulb presenting a surface with an intense sound reflection, and a large posterior reverberation artifact. The described appearance suggested the presence of air within the lesion.

Plain posteroanterior and lateral radiographs revealed an air filled mass in the neck (Fig 2). Considering the possibility of laryngocele CT was advised.

CT (Fig 3) demonstrated bilateral laryngocele (left bigger than right) with both internal and external component with no evidence any other underlying intralaryngeal or cervical pathology.

Barium swallow was performed to differentiate it from pharyngocele but was negative.

Correspondence

Dr. Kanchan Dhungel

Assistant Professor

Department of Radiodiagnosis and Imaging

B.P. Koirala Institute of Health Sciences, Dharan, Nepal

E-mail: kanchan_dhungel@hotmail.com 


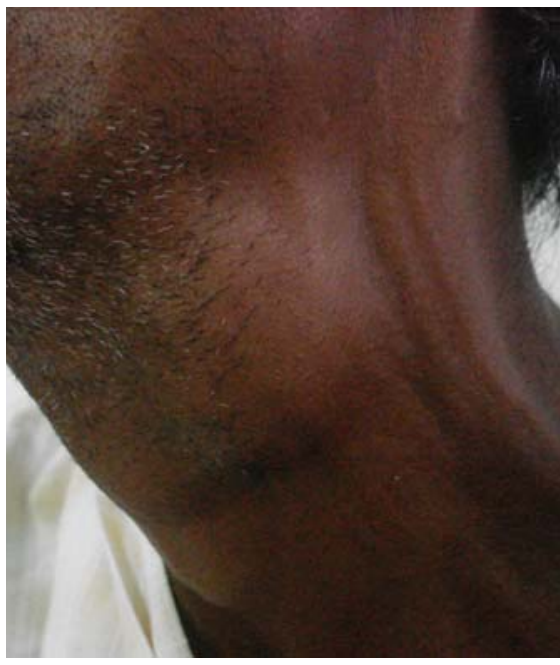

Fig 1: Photograph of the patient showing a visible bulge in the left side of neck

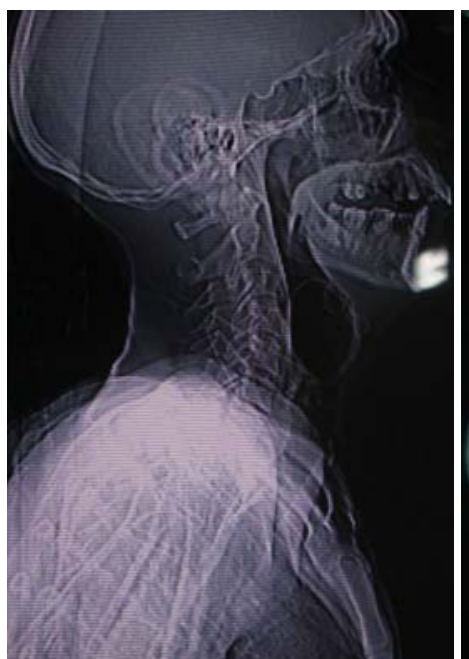

Fig 2: Plain radiograph demonstrating an air-filled mass in the neck

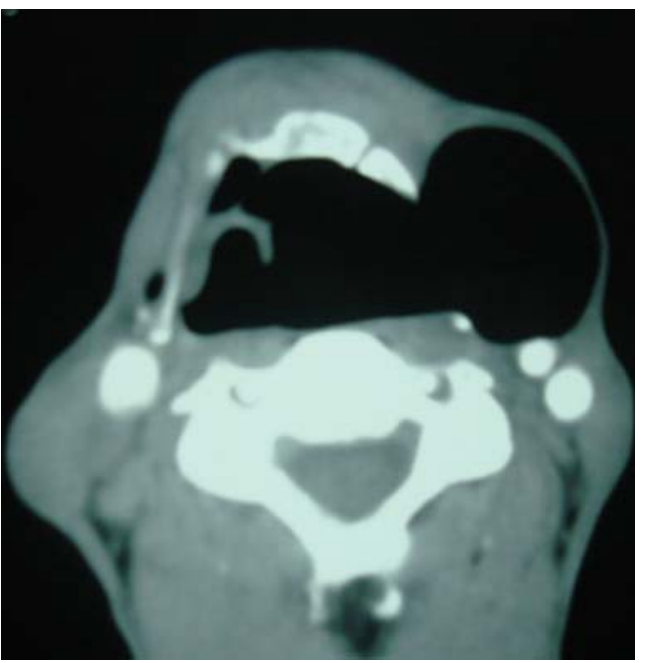

Fig 3: Multidetector CT images: axial reconstruction demonstrate bilateral laryngocele with both internal and external component communicating with the airway

\section{Discussion}

The laryngeal ventricles constitute a recess located between the false vocal cords above and the true vocal cords below. The anterosuperior aspect of this recess ends in a blind pouch called laryngeal saccule that extends upward through the paralaryngeal space, laterally limited by the thyrohyoid membrane, and medially by the laryngeal wall ${ }^{5,6,7}$. They vary in size which range from 5-15 $\mathrm{mm}$ in length, and typically may be observed in up to $30 \%$ of the adult population on CT studies ${ }^{5}$.

Laryngocele is a rare, benign dilatation of the laryngeal saccule that may extend internally into the airway or externally through the thyrohyoid membrane. Many laryngoceles are asymptomatic; sometimes they may cause a cough, hoarseness, stridor, sore throat and may present as a swelling on one or both sides of the neck. Laryngoceles limited to the interior of the larynx are called internal, while those that protrude laterally into the neck are called external ${ }^{4,8}$. Our patient had bilateral laryngocele with both internal and external component.

Stell and Maran reviewed nearly 100 cases in the English literature and found the incidence of one per year per 2,500,000 populations and found them to be unilateral in $85 \%$ and bilateral in $15 \%$ of cases $^{9}$.

The aetiology of the condition is unknown and unclear $^{10}$. There are several proposed mechanisms for laryngocele formation. In neonates, they are presumed to be remnants of the lateral air sacs seen in other higher primates. In adults, they can represent as congenital enlargement of the saccule or an acquired lesion associated with increased intraluminal pressure. The association of laryngoceles with laryngeal carcinoma and with occupations that involve long periods of forced expiration supports this notion ${ }^{11}$.

Aetiopathogenesis of laryngoceles is considered as multifactorial, and is related to the increase in the transglottic pressure, a factor usually present in glassblowers or musicians who play wind instruments ${ }^{12}$.

There is a rare, but well-documented, association of laryngocele with laryngeal carcinoma

Supraglottic carcinoma is the most common ${ }^{13}$. Therefore, if a laryngocele is detected clinically or radiologically, carcinoma must be ruled out by appropriate investigation ${ }^{14}$. In our case there was no such predisposing factor to increase the transglottic pressure.

The radiological diagnosis of laryngoceles previously has been limited to plain radiography, xerography, plain film tomography, and contrast laryngography. The lateral radiograph of the neck may show a well-circumscribed air collection suggestive of a laryngocele. When a laryngocele is predominantly filled with fluid rather than air (complicated laryngocele), differentiating it from any other soft-tissue mass may be impossible. Contrast laryngography can show the mass effect of internal laryngoceles, and fluoroscopic visualization 
of the larynx may help in the diagnosis of complicated laryngoceles if compressibility of the cyst can be demonstrated during phonation ${ }^{15}$.

Imaging studies play a significant role in the diagnosis of this lesion, and many authors suggest that CT is the gold standard, with MRI playing an adjuvant role in the diagnosis of laryngoceles ${ }^{17}$. CT scan has proved to be the most accurate imaging method in defining the spatial relationship between the laryngocele and the laryngeal structures and extra-laryngeal soft tissues, in differentiating the laryngocele from other cystic formations and in identifying the coexistence of a laryngeal cancer ${ }^{17,13}$. Ultrasonography is generally utilized for initial evaluation of cervical masses, mainly for differentiating the nature of the lesion as well as defining its contents and location ${ }^{18}$. In our patient, as USG demonstrated air containing lesion in the left submandibular region one of our differential diagnosis was laryngocele.

The diagnosis may be established by radiographs, an air filled space often being demonstrated on a plain film making it a worthwhile screening test for puzzling hoarseness though more detailed information may be gained from laryngeal CT scan.

\section{Conclusion}

In our opinion, the present case is of particular interest since the patient was affected by a large laryngocele unrelated to his profession without any predisposing factors. It is mandatory, in any patient presenting with a soft cervical mass, even if not a wind instrument player or a glass blower, to exclude the possibility of a laryngocele. In the present case, laryngocele was not associated with laryngeal cancer, but it is most important to remember and to consider the possibility of this association.

\section{References}

1. Holinger LD, Barnes DR, Smid LJ, Holinger PH. Laryngocele and saccular cysts. Ann Otol Rhinol Laryngol. 1978 ; 87: 675-85.

2. Saleh EM, Mancuso AA, Stringer SP. CT of submucosal and occult laryngeal masses. $\mathrm{J}$ of comput Assist Tomogr. 1992; 16:87-93.

3. Larry DJ. Laryngocele: A case report and review. The journal of otolaryngology. 1983; 12: 6, 389-92.

4. Som PM. Cystic lesions of the neck. Postgrad Radiol. 1987; 7:209-36.
5. Swartz JD, D'Angelo AJ, Harnsberger HR, Zwillenberg S, Marlowe FI. The laryngeal mucocele: Imaging analysis of a rare lesion. Clin Imaging. 1990; 14:110 -5.

6. Nazaroglu H, Ozates M, Uyar A, Deger E, Simsek M. Laryngopyocele: signs on computed tomography. Eur J Radiol. 2000;33:63 -5.

7. Kumar G, Bradley PJ, Wastie ML. Case of the month. What a blow! Laryngocele. Br J Radiol. 1998;71:799 -800.

8. DeSanto LW. Laryngocele, laryngeal mucocele, large saccules, and laryngeal saccular cysts: A developmental spectrum. Laryn-goscope. 1974; 84: 1291-6.

9. Stell PM, Maran AGD. Laryngocele. J laryngol Otol. 1975; 89: 915-24.

10. Erdogmus B, Yazici B, Ozturk O, Ataoglu $\mathrm{S}$, Yazici S. Laryngocele in association with ankylosing spondylitis. Wien Klin Wochenschr. $2005 ; 117: 718-20$.

11. Norris CW. Pharyngoceles of the hypopharynx. Laryngoseope. 1979 ; 89: 1788-807.

12. Sobol SM, Bailey SB. Evaluation and surgical management of tumors of the neck: benign tumors. In: Thawley SE, Panje WR, Batsakis JG,Lindberg RD, editors. Comprehensive management of head and neck tumors. Philadelphia, PA: WB Saunders; 1999.p. 1435 -9.

13. Matino Soler E, Martinez Vecina V, Leon Vintro X, Quer Agusti M, Burgues Vila J, de Juan M. Laryngocele: clinical and therapeutic study of 60 cases. Acta Otorrinolaringol Esp.1995; 46:279-86.

14. Gil Tutor E. Laryngoceles: Clinical and therapeutic study. An Otorrinolaringol Ibero Am. 1991; 18: 451- 64.

15. Johnson TH Jr. Fioranelli RJ. Laryngeal cyst (filled laryngocele): laryngographic diagnosis. Radiology. 1969 ; 93:875 -7.

16. Curtin HD. The larynx. In: Som PM, Curtin $\mathrm{HD}$, editors. Head and neck imaging. 4th ed. St. Louis, MO: Mosby;2003.p. 1595-699.

17. Akbas Y, Unal M, Pata YS. Asymptomatic bilateral mixed type laryngocele and laryngeal carcinoma. Eur Arch Otorhinolaryngol. 2004; 261:307-9.

18. Youssefzadeh S, Steiner E, Turetschek K, GritzmannN,Kursten R, FranzP. The sonography of laryngeal cysts. Rofo. 1993;159:38 - 42. 